\title{
Evaluación de políticas socioeducativas: impacto del cargo de Coordinador de Curso en las trayectorias escolares en una escuela secundaria pública técnica de Córdoba (Argentina)
}

\author{
Evaluation of socio-educational policies: Course coordination position impact \\ on school trajectories in a technical public secondary school in Córdoba (Argentina)
}

Francisco Bertea

\begin{abstract}
RESUMEN
Actualmente 404,789 niños y jóvenes repiten y 98,043 abandonan la escuela secundaria en Argentina cada año, principalmente de sectores socioeconómicos vulnerables. En la Provincia de Córdoba se creó el cargo de Coordinación de Curso para abordar estos problemas en las trayectorias escolares. En la presente investigación cualitativa-cuantitativa de tipo evaluativa longitudinal analizamos el impacto del trabajo de un Coordinador de Curso a lo largo de cinco años en las trayectorias escolares de su escuela. Comparamos estadísticamente dos periodos de cinco años (2009-2013 y 2014-2018) de acuerdo a la presencia/ausencia del cargo. Seguidamente caracterizamos estadísticamente el comportamiento de las trayectorias escolares según el año de presencia del cargo. Encontramos una disminución en los indicadores de la eficacia interna del sistema educativo empleados: $8.1 \%$ en la tasa de no-promoción, $0.8 \%$ en la tasa de abandono escolar anual y $15.26 \%$ en la tasa de estudiantes en situación de riesgo escolar. Seguidamente, a partir del trabajo de campo y las entrevistas realizadas construimos tres narrativas que buscan dar un marco de comprensión a los resultados encontrados, en los que la pobreza de las familias de los estudiantes se presenta como uno de los elementos explicativos de la eficacia interna. Finalmente, esperamos que este estudio brinde una herramienta de evaluación del trabajo educativo en las trayectorias escolares a nivel institucional y de las políticas socioeducativas.
\end{abstract}

Palabras clave: vulnerabilidad educativa, equidad, justicia social, nivel medio, eficacia interna.

\begin{abstract}
Currently, 404,789 children and youth repeat and 98,043 drop out of secondary school in Argentina every year, mainly from vulnerable socioeconomic sectors. In the Province of Córdoba, the position of Course Coordination was created to address these problems in school trajectories. In the present qualitativequantitative longitudinal evaluative research, we analyze the impact of the work of a Course Coordinator over five years on the school trajectories of his school. We statistically compared two five-year periods (2009-2013 and 2014-2018) according to the presence/absence of the position. Next, we statistically characterize the behavior of school trajectories according to the year of presence of the position. We found a decrease in the indicators of the internal effectiveness of the educational system employed: $8.1 \%$ in the non-promotion rate, $0.8 \%$ in the annual dropout rate and $15.26 \%$ in the students in school risk rate. Subsequently, based on fieldwork and interviews we constructed three narratives that seek to provide a framework for understanding the results found, in which the poverty of the students' families is presented as one of the explanatory elements of internal efficiency. Finally, we hope that this study provides a tool for evaluating educational work in school trajectories at an institutional level and in socio-educational policies. Keywords: educational vulnerability; equity, social justice, internal efficacy.
\end{abstract}




\section{La Coordinación de Curso como política socioeducativa}

Actualmente a nivel latinoamericano y argentino se presentan diferentes problemáticas sociales (violencia, desempleo, abandono escolar, problemas socio-familiares, consumo problemático, etc.) que, más allá del propio malestar de la cultura, con la avanzada de políticas neoliberales y la consiguiente reducción del acceso a los derechos de la ciudadanía, se acentúan las situaciones de vulnerabilidad, desventaja social y sociosegregación, especialmente en aquellas sectores con menos recursos económicos.

En el ámbito educativo argentino de nivel medio se presentan políticas y estrategias institucionales inclusivas que buscan abordar los problemas sociales y mejorar las condiciones de accesibilidad al derecho a la educación, en clave justicia educativa. Es así que se han logrado avances significativos en la universalización de la escuela secundaria, con una mayor retención, incrementándose la matrícula (Ministerio de Educación, Cultura, Ciencia y Tecnología, 2018; Buchbinder, McCallum y Volman, 2019; Dirección General de Estadística y Censo, 2019; UEPC, 2014), incluyendo a sectores previamente excluidos (D’Aloisio, Arce y Arias, 2018; Paredes, 2018).

Sin embargo, de acuerdo a la información pública disponible, a nivel nacional se presenta una tendencia constante en el índice de repitencia entre los años 2011-2018 de alrededor del 10\% (Buchbinder, McCallum y Volman, 2019; Ministerio de Educación, Cultura, Ciencia y Tecnología, 2017, 2018), situación que llevó a que 810,550 alumnos repitieran su ciclo escolar en los años 2017 y 2018, y 200,521 alumnos abandonaran la escuela en los años 2016 y 2017 (Ministerio de Educación, Cultura, Ciencia y Tecnología, 2017, 2018).

Esta situación es más alentadora en la Provincia de Córdoba, donde en la última década se presenta una tendencia de disminución en los índices de repitencia y abandono escolar (Dirección General de Estadística y Censo, 2019). Más allá de esto, entre los años 2010-2018 han repetido 235,623 alumnos, y entre los años 20102017 han abandonado la escuela 138,170 alumnos (Ministerio de Educación, 2015, 2018). Actualmente, de un total de 329,729 alumnos en el año 2018, 24,400 repitieron (7.4\%) y en el año 2017 15,167 alumnos (4.6\%) abandonaron la escuela (Ministerio de Educación, 2018).

Se presentan así problemas en el rendimiento o eficacia interna del sistema educativo (Bottinelli, 2018; Paredes, 2018) argentino y cordobés, con variaciones entre

Francisco Miguel Fernando Bertea. Investigador becario doctoral de ConiCET, Universidad Nacional de Córdoba, Argentina. Es educador del Instituto Simón Bolívar Anexo Villa Libertador y Coordinador de Curso (2013-2019). Realizó una especialización en Políticas Socioeducativas (Ministerio de Educación de la Nación) y en Gestión y Conducción del Sistema Educativo y sus Instituciones (FLACSO). Entre sus publicaciones recientes se encuentra el libro colectivo Diario de escuela. Narraciones de Coordinadorxs de Curso (2018). Es miembro del Grupo Clínico del Hospital Alta Gracia Dr. Arturo U. Illia y de la red-colectivo “Danzas del sur”. Correo electrónico: fmfbertea@gmail.com. ID: https://orcid.org/0000-0003-3978-6445. 
las provincias, que afectan las trayectorias escolares (Terigi, 2015; D'Aloisio, Arce y Arias, 2018) de muchos niños y jóvenes, vulnerando su derecho a la educación.

En este contexto, la organización del sistema educativo y las dinámicas escolares sostienen un sistema educativo de inclusión-excluyente (Maturo, 2018; D’Aloisio, Arce y Arias, 2018; Gvirtz y Oría, 2010; Ortiz y Zacarías, 2020) en el cual, más allá de los esfuerzos que docentes, preceptores, tutores y directivos realizan, la escuela secundaria termina excluyendo a muchos alumnos, además de exponerlos a escolarizaciones de baja intensidad (Finnegan y Serulnikov, 2014).

Los problemas socioeducativos de repitencia y abandono afectan principalmente a los estudiantes de sectores de menores ingresos económicos o pobres, más aún en zonas rurales (Paredes, 2018; UNICEF, 2016; Rivas, 2015). Mientras que un 42\% de los niños y adolescentes argentinos viven bajo la línea de pobreza (5,5 millones niños) (UNICEF, 2019), en Córdoba se ha incrementado la pobreza, de modo que en el 2018 hubo un 35.7\% personas pobres y 7.5\% indigentes (CIPPES, 2019), índices que se incrementaron en los niños, de los cuales $47.42 \%$ son pobres (485 mil niños) y $10.13 \%$ indigentes (103 mil niños) (CIPPES, 2018).

Una de las estrategias estatales para el abordaje de estos problemas sociales son las políticas socioeducativas. Se trata de políticas orientadas a la inclusión e igualdad de oportunidades, desde la ampliación de los universos culturales, el fortalecimiento de las trayectorias escolares de niños y jóvenes en contextos socio-económicos vulnerables (DNPS, s.f.a.; Finnegan, Montesinos y Schoo, 2019), presentando como sentido último una educación de calidad con igualdad (DNPS, s.f.b.; Finnegan y Serulnikov, 2014).

Actualmente las políticas socioeducativas presentan diferentes programas, por ejemplo: CAI (Centros de Actividades Infantiles), CAJ (Centros de Actividades Juveniles), ${ }^{1}$ Proyecto para la Prevención del Abandono Escolar, entre otros ${ }^{2}$ (DNPS, s.f.b.; Finnegan y Serulnikov, 2014).

A partir de la obligatoriedad de la escuela secundaria establecida por la Ley de Educación Nacional N² 26.206 (Congreso Argentino, 2006), en el año 2009 en la provincia de Córdoba se creó la figura del "Coordinador de Curso" en el ámbito de nivel medio. Regulada por la Res. 1613/09 (Ministerio de Educación, 2009), su función se focaliza en trabajar las condiciones de acceso, permanencia y egreso de los estudiantes, desde un enfoque de inclusión y calidad educativa (Martino y Del Valle, 2011; Martino, 2012; Acosta, Bertea, Correa, Dallacosta y Hennao, 2018),

1 Los CAI y CAJ son programas socioeducativos que brindan espacios de educación no formal por medio del arte, juego, recreación y deporte, en espacios curriculares y extra-curriculares. Este programa surgió a nivel nacional en el año 2001 para afrontar la crisis social, pasando a la esfera provincial en el año 2019.

2 Actualmente estos programas socioeducativos se encuentran desfinanciados, como producto de las políticas del anterior gobierno nacional (2015-2019) (Redacción Córdoba, 2019). 
singularizando su quehacer profesional a los problemas, recursos y potencias de la comunidad educativa a la que pertenece (Lavalle, 2015; Acosta et al., 2018) y a los modos subjetivos de construir su función (Martino y Del Valle, 2011).

Los objetivos que orientan el trabajo del Coordinador de Curso son mejorar las trayectorias escolares, socialización, convivencia, aprendizajes significativos, participación, formación ciudadana y accesibilidad de los derechos de los niños y jóvenes. Estos profesionales centran su trabajo educativo en los estudiantes con dificultades y/o situaciones de riesgo escolar, al valorar la vulneración de sus derechos a la educación (Acosta et al., 2018).

Seguidamente, el trabajo cotidiano de acompañamiento a las trayectorias escolares que realizan requiere prevenir, promover y asistir situaciones problemáticas psicosociales (problemas de aprendizaje, problemas de convivencia, violencia familiar, abuso sexual, consumo problemático de sustancias, labilidad en el oficio de ser estudiantes, labilidad en el acompañamiento familiar, malestar institucional, etc.). Para ello facilitan procesos de articulación al interior de su comunidad educativa (entre estudiantes, docentes, preceptores, directivos y familia) y al exterior (áreas de Niñez, Adolescencia y Familia locales, dispensarios, UDEE, ${ }^{3}$ EPAE, ${ }^{4}$ etc.) (Acosta et al., 2018; Ministerio de Educación, 2009; Lavalle, 2015).

Actualmente la mayoría de las escuelas secundarias de la Provincia de Córdoba cuentan con este agente en su plantel, ascendiendo a más de 400 Coordinadores de Curso en todo el territorio provincial.

El trabajo que realizan los Coordinadores de Curso comparte algunos puntos con otros cargos similares de otras provincias. Por ejemplo, "Profesor Acompañante de Trayectorias" (PAT) en Buenos Aires (Gobierno de la Provincia de Buenos Aires, 2019), "Coordinador pedagógico" del proyecto "Trayectoria Escolar Protegida" (TEP) en Mendoza (Finnegan, Montesinos y Schoo, 2019), "Profesor Orientador Tutor" (POT) en Chubut (CITA), "Coordinador de Curso" y docente de "Atención a las Trayectorias Escolares" (ATE) en La Pampa, y "Docentes de Opción” y "Profesores de Orientación y Tutorías" en San Juan (Finnegan y Serulnikov, 2014).

En la actualidad, si bien el cargo de Coordinador de Curso no es reconocido formalmente como una política socioeducativa, entendiendo que los actores escolares reconocen diferentes estrategias educativas como parte de dicho campo (Finnegan y Serulnikov, 2014) y que las políticas son construidas en complejos procesos de negociación, disputa y reconocimiento, consideramos posible pensar este cargo como parte de dichas políticas.

3 Unidad de Desarrollo Regional, Secretaría de Niñez, Adolescencia y Familia, Ministerio de Justicia y Derechos Humanos.

4 Equipo de Profesionales de Apoyo a las Escuelas, Subsecretaría de Promoción de la Igualdad y Calidad Educativa, Ministerio de Educación. 
Esta relación es coherente a la luz de que la Coordinación de Curso comparte con las políticas socioeducativas objetivos (promover la inclusión y calidad educativa, trabajando con las trayectorias escolares) y algunas modalidades de acción. Respecto a esto último encontramos coincidencias en los recursos y estrategias de trabajo, empleando el contacto personal y afectivo, una escucha atenta, involucramiento, contención, vínculos de confianza y más simétricos, y disposición de tiempo para acompañar a los estudiantes en sus problemas y conflictos (Finnegan y Serulnikov, 2014); como también un trabajo articulado entre actores escolares e interinstitucionales locales y regionales, y estrategias educativas formales y no formales -culturales, recreativas, deportivas y artísticas- (Acosta et al., 2018).

\section{Riesgo escolar: entre problemas socioeducativos y situación socioeconómicas}

El cargo de Coordinador de Curso trabaja con las trayectorias escolares a nivel individual e institucional. Uno de los problemas transversales que aborda es el fracaso escolar, como contracara de la eficacia escolar (Bottinelli, 2018).

El fracaso escolar se asocia a múltiples factores, internos y externos al sistema escolar; uno de los factores externos es el nivel socioeconómico de la familia (Román, 2013; Secretaria de Educación Pública, 2012; UNICEF, 2016; Bottinelli, 2018).

La bibliografía especializada plantea una relación entre las situaciones socioeconómicas ${ }^{5}$ y las trayectorias escolares de los estudiantes (López, 2005; Dussel, 2008; CEPAL, 2008; Román, 2013; UNICEF, 2016; Aristimuño, 2017). Por ejemplo, mientras el $20 \%$ de los jóvenes latinoamericanos pertenecientes a los segmentos más pobres de la población (quintil de ingresos familiares más bajo) concluyen la enseñanza secundaria, cerca del $80 \%$ de los jóvenes del segmento más rico de la población (quintil de ingresos familiares más altos) lo hacen (CEPAL, 2008; Román, 2013).

La situación socioeconómica de las familias se encuentra asociada a los capitales culturales familiares. Las familias con situaciones socioeconómicas desfavorables y trayectorias escolares interrumpidas presentan capitales culturales "empobrecidos", sin haber incorporado conocimientos, competencias, hábitos, etc., de algunas instituciones (escuela secundaria, universidad, etc.) al verse interrumpida su trayectoria escolar (Bottinelli, 2018). Así, estas familias no lograrían transmitir a sus hijos los capitales culturales necesarios para aprender el oficio de ser estudiantes y lograr una escolarización exitosa (Martino, 2012), y la escuela y el Estado no lograrían generar

5 Nos referimos por situación socioeconómica a los ingresos económicos familiares, y el consiguiente análisis estadístico por quintiles. Se entiende por quintil un cálculo de orden de una población, de acuerdo a la distribución del ingreso económico en una región dada, desde el individuo más pobre al más adinerado, dividiendo en cinco partes dicha población. El primer quintil corresponde a la porción más pobre, mientras que el quinto quintil corresponde al sector más rico o de mayores ingresos económicos. 
estrategias estructurales de inclusión, reproduciéndose así la desigualdad socioeconómica (pobreza) desde una desigualdad educativa (fracaso escolar).

En otras palabras, la desigualdad social genera desigualdad educativa, que a su vez genera desigualdad social, reproduciéndose a sí misma (Bolívar, 2005; UNICEF, 2019), dinámica atravesada por las lógicas del sistema neoliberal capitalista, que dificulta la implementación de políticas de inclusión educativas (Ortiz y Zacarías, 2020).

En este marco, si bien la pobreza es un predictor del fracaso escolar, "no todos los pobres abandonan el sistema escolar, ni todos aquellos hijos de madres con baja escolaridad o analfabetas llegan a ser desertores" (Román, 2013, p. 52). Así, por un lado, mientras que algunos autores plantean que se presentan excepciones a esta asociación (Dussel, 2008; D’Aloisio, Arce y Arias, 2018; Bottinelli, 2018), otros cuestionan la relevancia de estos factores externos, planteando que hay otras variables igual o más relevante (por ejemplo, la significatividad de la enseñanza para los estudiantes, los recursos escolares, el clima escolar, etc.) (Aristimuño, 2017; Bottinelli, 2018).

Sin embargo, las condiciones de carencia socioeconómica y cultural sitúan a muchos niños y jóvenes en una situación de vulnerabilidad o riesgo social, y fragilizan la tarea educativa en clave equidad (Serra y Canciano, 2006) que realizan los Coordinadores de Curso, generando así mismo riesgo o vulnerabilidad educativa.

La palabra vulnerabilidad hace referencia a la potencialidad negativa o probabilidad de ser dañado o herido, denotando riesgo, fragilidad o indefensión. Siguiendo a Díaz López y Pinto Loría (2017) y Sabuda (2009), entendemos por vulnerabilidad social la incapacidad de una comunidad y sus instituciones de resolver los problemas de precarización de la vida, producto de su propio funcionamiento, situación que afecta a determinadas personas y no a otras, de acuerdo a la posición que ocupan en el campo social. En ese sentido, hablar de vulnerabilidad social implica comparar condiciones materiales de existencia de grupos sociales diferentes, como por ejemplo capitales económicos y culturales familiares, asistencia social, etc. (Vega, 2017). En el ámbito educativo, entendemos por riesgo o vulnerabilidad escolar a un momento de la vida educativa de los estudiantes, producto de situaciones sociofamiliares y personales, que los expone a situaciones de bajo rendimiento y desempeño educativo, así como también a otros problemas escolares (problemas de aprendizaje, indisciplina, desmotivación, problemas de aprendizaje, problemas de convivencia, abandono escolar, etc.).

Algunos de los indicadores de la vulnerabilidad escolar que emplean los Coordinadores de Curso son: repitencia, sobredad, inasistencia frecuente o crónica, problemas psicológicos, problemas de convivencia escolar, problemas familiares y riesgos psicosociales (violencia familiar, abuso sexual, consumo de sustancias, embarazo adolescente, etc.) (Díaz y Pinto, 2017; Secretaria de Educación Pública, 2012; Adrogué y Orlicki, 2018). 
Estas situaciones de riesgo escolar llevan a trayectorias escolares no lineales o interrumpidas, generándose una clara distancia entre la trayectoria teórica y las trayectorias reales (Terigi, 2015; UNICEF, 2016).

A nivel individual, el riesgo escolar se construye procesualmente a lo largo de las trayectorias educativas de cada estudiante, pudiendo tener una duración variable, de meses o años. Por otro lado, a nivel social, es producto de situaciones socioeconómicas y culturales familiares, así como también condiciones institucionales (Díaz y Pinto, 2017; Vega, 2017; Ritacco y Amores, 2016; Prieto, 2015; Sabuda, 2009).

Sin embargo, cuando analizamos las causas de los problemas socioeducativos desde la mirada de sus actores, por un lado, la mayoría de los estudiantes se autoresponsabilizan de sus problemas educativos, así como también sus familias (Prieto, 2015; Sabuda, 2009), más allá de que se trate de un problema social estructural. Esta auto-atribución de las causas de los problemas educativos por parte de estudiantes y familias es efecto de la misma opresión y naturalización de las condiciones sociales y educativas opresivas (Freire, 2012). Por otro lado, docentes, preceptores y directivos plantean que se trata de un problema del sistema educativo argentino, que no logra dar "respuestas adecuadas a las necesidades educativas de todos los alumnos y no compensan las limitaciones de origen familiar o social que afectan a jóvenes procedentes de familias problemáticas y de medios desfavorecidos socioculturalmente" (Díaz y Pinto, 2017, p. 6); sin interpelar y modificar su tarea educativa y las lógicas institucionales de exclusión que sostienen (Borzone y Rosemberg, 2000).

En este panorama, si bien la escuela no tiene control ni puede trabajar los aspectos que desencadenan el riesgo social (capitales económicos y culturales familiares), sí puede abordar los indicadores del riesgo educativo (bajo rendimiento, problemas de aprendizaje, ausentismo, desmotivación, repitencia, violencia familiar, etc.) (Prieto, 2015), para lo cual es necesario contar con profesionales con formación especializada en estas problemáticas socioeducativas. En el caso del sistema educativo cordobés, uno de estos profesionales es el Coordinador de Curso.

Enmarcados en los estudios de eficacia escolar (Bottinelli, 2018), interesados por conocer los efectos o impacto de las políticas socioeductivas en las trayectorias educativas en la Provincia de Córdoba, encontramos numerosos antecedentes regionales que analizan el impacto de programas o proyectos socioeducativos, tanto cualitativamente (Finnegan y Serulnikov, 2014; Olmos, 2016; Finnegan, Montesinos y Schoo, 2019) como cuantitativamente (Ministerio de Educación, 2008; Gvirtz y Oría, 2010; Gobierno de la Provincia de Buenos Aires, 2019). Específicamente, respecto a la Coordinación de Curso, si bien se presentan estudios que investigan cualitativamente su impacto (por ej. Acosta et al., 2018; Lavalle, 2015; Martino, 2012), no encontramos antecedentes que evalúen el impacto estadístico en las trayectorias escolares de los estudiantes. 
Considerando el área de vacancia y reconociendo que el cargo de Coordinación de Curso cuenta con once años de su existencia, en la presente investigación realizamos un estudio de caso, para lo cual evaluamos el impacto estadístico de la Coordinación de Curso en las trayectorias escolares en una escuela secundaria pública técnica ${ }^{6}$ a lo largo de cinco años. Seguidamente caracterizamos estadísticamente el comportamiento de las trayectorias escolares según el año de presencia del cargo de Coordinación de Curso en la escuela estudiada.

\section{Metodología}

Realizamos una investigación-acción (Fals, 1985; Montero, 2006; Vega, 2017) en el marco de un estudio mixto cualitativo-cuantitativo de tipo evaluativo descriptivo (Cohen y Franco, 1992) y longitudinal, de caso único; realizado desde una perspectiva etnográfica, ecológica (Taylor y Bogdan, 1985; Lassiter, 2005) y domiciliaria (Torres, 2016).

En el mismo sistematizamos el proceso de trabajo cotidiano (Jara, 2012; Bell y Aggleton, 2016) de un Coordinador de Curso a lo largo de cinco años, focalizando en la evaluación estadística del impacto de su trabajo en las trayectorias escolares (Ministerio de Educación, 2008; Paredes, 2018; Diniece, s.f.). Este problema de investigación fue definido como producto de un proceso de problematización de la realidad vivida, a partir de las necesidades sentidas y los problemas identificados por los actores educativos (Fals, 1985; Montero, 2006; Vega, 2017).

Empleamos como técnicas de estudio entrevistas abiertas (Taylor y Bogdan, 1985) con el Coordinador de Curso y otros actores institucionales (directivos, ex-directivos, secretaria, preceptores y docentes), participación observante, diario de campo, análisis de documentos (plan de acción anual del Coordinador de Curso) y análisis descriptivo estadístico (Ministerio de Educación, 2008; Paredes, 2018; DinieCE, s.f.).

Asistimos semanalmente a la escuela, compartiendo con actores de la comunidad educativa en los espacios de recreos, sala docente, reuniones de personal, ingresos y egresos, procedimiento que nos permitió conocer comprensivamente y en profundidad los fenómenos socio-educativos en estudio.

Para el análisis descriptivo estadístico del impacto del trabajo del Coordinador de Curso desde una perspectiva ecológica empleamos los indicadores que el profesional emplea para evaluar la situación educativa de su escuela, a saber: tasa de no-promoción, tasa de abandono escolar anual y tasa de estudiantes en situación de riesgo escolar.

6 Es importante señalar que en Argentina casi una quinta parte de los estudiantes de la educación secundaria asisten a escuelas técnicas (Buchbinder, McCallum y Volman, 2019). Específicamente, en la Provincia de Córdoba, este valor ascendió al 31\% en el año 2018 (Ministerio de educación, 2018). 
Realizamos la selección del caso en estudio de acuerdo a un criterio de disponibilidad y accesibilidad.

La escuela estudiada es una escuela secundaria pública técnica, ubicada a 50 kilómetros de Córdoba capital, en una zona semi-rural, con una matrícula de entre 300 y 400 estudiantes $^{7}$ y un plantel de 70 docentes.

El presente estudio contempla los estándares éticos dispuestos por el marco normativo vigente (Congreso Argentino, 2000; Presidencia de la Nación Argentina, 1970) respecto al consentimiento informado y confidencialidad, preservando el anonimato de personas e instituciones.

\section{Análisis de datos}

Para el análisis cualitativo realizamos un análisis hermenéutico (De Souza, 2009) de los registros obtenidos, empleando como criterios la pertinencia temática y objetividad (Gibbs, 2012; Rodríguez, Gil y García, 1996). Empleamos como estrategia de triangulación la consulta con expertos (Coordinadores de Curso y docentes de otras escuelas), respecto a los análisis estadísticos y las conclusiones arribadas.

Por otro lado, realizamos un análisis de la presencia de estudiantes con 34 inasistencias o más por ciclo lectivo, en el periodo estudiado.

Para el análisis cuantitativo realizamos un análisis estadístico de las trayectorias escolares a lo largo de cinco años. Las estadísticas fueron confeccionadas manualmente, ${ }^{8}$ con el aporte de una preceptora y docente, a partir de los Registros de asistencia de preceptoría y los Libretones, ${ }^{9}$ trabajo que realizamos dos veces para chequear y corregir errores. La tarea de revisión global fue realizada por el investigador.

Considerando que el cargo de Coordinador de Curso fue creado en la escuela estudiada a inicios del año 2014, describimos estadísticamente las trayectorias escolares en el periodo 2005-2018, a modo de disponer de una perspectiva amplia y compleja del comportamiento de cada estadístico. Sobre esta base, focalizamos el análisis en la comparación de dos periodos de cinco años (2009-2013 y 2014-2018), considerando que en el primer periodo no existía cargo de Coordinador de Curso y en el segundo periodo sí.

La matrícula de la escuela varió a largo de los cinco años que duró el estudio de 300 a 400 estudiantes.

8 Se trabajó en la confección de estadísticas de la escuela estudiada debido a que el Coordinador de Curso expresó que la estadística confeccionada por la Dirección General de Educación Técnica y Formación Profesional (DGETyFP) no coincidía con las estadísticas de su escuela, situación que también fue informada por cinco Coordinadores de Curso de otras escuelas.

9 Empleamos los registros de asistencia de preceptoría (documento donde se anotan las asistencias e insasistencias de los estudiantes) y los Libretones (documento donde se anota la trayectoria educativa de cada curso, por estudiante, por ciclo lectivo: notas, asistencia y amonestaciones por trimestre; en el mismo se incluyen las notas de los exámenes de diciembre y febrero, así como también las materias adeudadas). 
Presentamos a continuación la definición de cada estadístico empleado:

- Tasa de no-promoción: cociente entre alumnos matriculados que no promocionaron el ciclo lectivo en curso y alumnos matriculados al inicio del ciclo lectivo (Ministerio de Educación, 2018). Son nombrados como alumnos repitentes, categoría que incluye a los estudiantes que abandonaron la escuela.

- Tasa de abandono anual: cociente entre alumnos matriculados que abandonaron el sistema antes de finalizar el año escolar y alumnos matriculados al inicio del ciclo lectivo (Ministerio de Educación, 2018). En la escuela estudiada se los denomina como alumnos libres, ${ }^{10}$ que dejan de concurrir a la escuela sin solicitar pase.

- Tasa de estudiantes en situación de riesgo escolar: cociente entre alumnos matriculados con cinco o más asignaturas sin promedio al final del ciclo lectivo en curso y alumnos matriculados al inicio del ciclo lectivo.

En todos los casos analizamos las variaciones entre los promedios de los estadísticos de los periodos en estudio (2009-2013 y 2014-2018), comparando con las estadísticas a nivel provincial (totalidad de las escuelas secundarias de la Provincia de Córdoba), a nivel de las escuelas técnicas (escuelas secundarias técnicas de la Provincia de Córdoba) y a nivel departamental (escuelas secundarias del Departamento de la Provincia de Córdoba donde se ubica la escuela secundaria estudiada), cuando se contó con la información estadística.

Finalmente realizamos una síntesis del comportamiento de los estadísticos analizados de acuerdo al año de presencia del cargo de Coordinación de Curso en la escuela estudiada, comparando las variaciones anuales, empleando la notación de Sabuda (2009): disminución (-), disminución marcada $(-)$, incremento $(+)$ e incremento marcado $(++)$.

\section{Resultados}

Presentamos a continuación los resultados de la evaluación estadística del impacto del trabajo de la Coordinación de Curso en las trayectorias escolares.

\section{No-promoción}

En la escuela estudiada se presenta una tendencia a la disminución no lineal en la tasa de no-promoción en el periodo 2005-2018 (tabla 1 y figura 1). Observamos una disminución del 8.1\% en la tasa de no-promoción en el periodo 2014-2018 (24.6\%) respecto al periodo 2009-2013 (32.7\%) (tabla 2).

10 Categoría empleada en la escuela estudiada, que hace referencia a la condición de cursada, sin hacer referencia a su situación de promoción. Es importante aclarar que estos alumnos no promocionan su año escolar, de modo que si se matriculan el año siguiente son considerados como repitentes. 
Comparativamente, esa tendencia a la disminución es marcadamente mayor que la sucedida a nivel provincial (2.2\%), a nivel de las escuelas técnicas $(2 \%)$ y a nivel departamental (4.5\%) en el periodo entre $2005-2017,{ }^{11}$ por $5.9,6$ y 3.6 puntos percentuales correspondientemente, tendencias que también son no-lineales (tabla 3, 4, y 5).

A nivel provincial, de las escuelas técnicas y departamental se presenta una disminución marcada en el periodo 2013-2014, si bien en la escuela estudiada observamos que la disminución es mayor (13 puntos percentuales), 11 puntos percentuales más que a nivel provincial, 10.2 puntos a nivel de las escuelas técnicas y 6.2 a nivel departamental.

Tabla 1. Tasa de no-promoción (2005-2018).

\begin{tabular}{|l|l|l|l|l|l|l|l|l|l|l|l|l|l|l|}
\hline & 2005 & 2006 & 2007 & 2008 & 2009 & 2010 & 2011 & 2012 & 2013 & 2014 & 2015 & 2016 & 2017 & 2018 \\
\hline No prom. Escuela (\%) & 42.4 & 37.9 & 34.9 & 29.2 & 38.6 & 30.4 & 28.3 & 32.8 & 33.5 & 20.5 & 24.6 & 33.7 & 22.5 & 21.8 \\
\hline \% No prom. Tot. Provincia & 17.1 & 18.4 & 17.9 & 17.5 & 15.9 & 17.0 & 15.9 & 14.9 & 15.3 & 13.5 & 13.7 & 13.8 & 13.2 & \\
\hline \% No prom. Técn. Prov. & & & & & & & 20 & 19.1 & 19.9 & 17.1 & 18.6 & 17.3 & & \\
\hline \% No prom. Dpto. reg. ed. & & & & & & & 20.6 & 19.1 & 19 & 12.2 & 17.1 & 15.7 & & \\
\hline
\end{tabular}

Tasa de no-promoción por año en la escuela secundaria estudiada, en las escuelas secundarias de la Provincia de Córdoba, en las escuelas secundarias técnicas de la Provincia de Córdoba y en el Departamento de la escuela secundaria estudiada (2005-2018).

Fuente: Construcción personal.

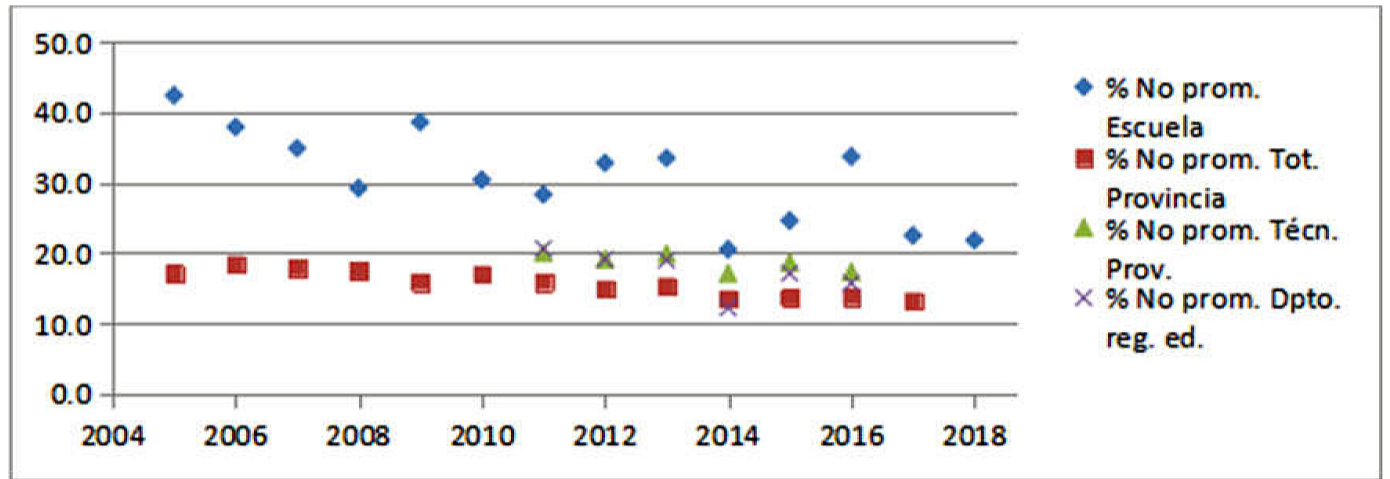

Figura 1. Tasa de no-promoción (2005-2018).

Tasa de no-promoción en la escuela secundaria estudiada, en las escuelas secundarias de la Provincia de Córdoba, en las escuelas secundarias técnicas de la Provincia de Córdoba y en el Departamento de la escuela secundaria estudiada (2005-2018).

Fuente: Construcción personal.

11 De acuerdo a la disponibilidad estadística, estudiamos la tasa de no-promoción en cada nivel de análisis en los siguientes periodos: 2005-2017 para la tasa de no-promoción provincial (Área de Información Educativa, 2008, 2012; Área de Estadística e Información Educativa, 2015; Ministerio de Educación, 2018) y 2011-2016 para la tasa de no-promoción de las Escuelas Técnicas y Departamental (Dirección General de Educación Técnica y Formación Profesional, 2018). En ese sentido, el Área Estadística del Ministerio de Educación de la Provincia de Córdoba nos informó que no dispone de registros anteriores al 2011 sobre las escuelas técnicas (comunicación personal). 
Tabla 2. Variación de tasa de no-promoción en la escuela secundaria estudiada (2009-2013 y 2014-2018).

\begin{tabular}{|l|l|l|}
\hline Periodo & 2009-2013 & 2014-2018 \\
\hline Promedio (\%) & 32,7 & 24,6 \\
\hline Variación (\%) & \multicolumn{2}{|c|}{8,1} \\
\hline
\end{tabular}

Fuente: Construcción personal.

Tabla 4. Variación de tasa de no-promoción en las escuelas secundarias técnicas de la Provincia de Córdoba (2009-2013 y 2014-2018).

\begin{tabular}{|l|l|l|}
\hline Periodo & 2011-2013 & 2014-2016 \\
\hline Promedio (\%) & 19,7 & 17,6 \\
\hline Variación (\%) & \multicolumn{2}{|c|}{2} \\
\hline
\end{tabular}

Fuente: Construcción personal.
Tabla 3. Variación de tasa de no-promoción en las escuelas secundarias de la Provincia de Córdoba (2009-2013 y 2014-2018).

\begin{tabular}{|l|l|l|}
\hline Periodo & 2009-2013 & 2014-2017 \\
\hline Promedio (\%) & 15,8 & 13,6 \\
\hline Variación (\%) & \multicolumn{2}{|c|}{2,2} \\
\hline
\end{tabular}

Fuente: Construcción personal.

Tabla 5. Variación de tasa de no-promoción en las escuelas del Departamento de la escuela secundaria estudiada (2009-2013 y 2014-2018).

\begin{tabular}{|l|l|l|}
\hline Periodo & 2011-2013 & 2014-2016 \\
\hline Promedio (\%) & 19,5 & 15 \\
\hline Variación (\%) & \multicolumn{2}{|c|}{4,5} \\
\hline
\end{tabular}

Fuente: Construcción personal.

\begin{abstract}
Abandono anual
En la escuela estudiada se presenta una tendencia a la disminución no lineal en el porcentaje de abandono escolar anual en el periodo 2005-2017 (tabla 6 y figura 2). Seguidamente se presenta una disminución del $0.8 \%$ en la tasa de abandono escolar anual en el periodo 2014-2018 (7.7\%) respecto al periodo 2009-2013 (6.9\%) (tabla 7). A nivel provincial también se presenta una disminución de $1.1 \%$, tendencia mayormente lineal, excepto por un pico de incremento en el año 2007 (tabla 8).

Comparativamente, la tendencia a la disminución de la escuela estudiada $(0.8 \%)$ es menor que la sucedida a nivel provincial $(1.1 \%)$ por 0.3 puntos porcentuales.
\end{abstract}

Tabla 6. Tasa de abandono anual en la escuela secundaria estudiada y en las escuelas secundarias de la Provincia de Córdoba (2005-2018).

\begin{tabular}{|l|l|l|l|l|l|l|l|l|l|l|l|l|l|l|}
\hline & 2005 & 2006 & $\mathbf{2 0 0 7}$ & $\mathbf{2 0 0 8}$ & $\mathbf{2 0 0 9}$ & $\mathbf{2 0 1 0}$ & $\mathbf{2 0 1 1}$ & $\mathbf{2 0 1 2}$ & $\mathbf{2 0 1 3}$ & $\mathbf{2 0 1 4}$ & $\mathbf{2 0 1 5}$ & $\mathbf{2 0 1 6}$ & $\mathbf{2 0 1 7}$ & $\mathbf{2 0 1 8}$ \\
\hline Abandono anual Esc. (\%) & 12,0 & 14,2 & 10,3 & 9,0 & 6,4 & 6,3 & 8,3 & 10,1 & 7,3 & 8,6 & 7,6 & 6,1 & 5,6 & 6,7 \\
\hline Abandono anual Prov. (\%) & 8,1 & 7,3 & 7,7 & 7,1 & 6,4 & 6,2 & 6,2 & 6,1 & 5,8 & 5,5 & 5,0 & 5,0 & 4,6 & \\
\hline
\end{tabular}

Fuente: Construcción personal.

Tabla 7. Variación de tasa de abandono anual en la escuela secundaria estudiada en los periodos 2009-2013 y 2014-2018.

\begin{tabular}{|l|l|l|}
\hline Periodo & 2009-2013 & 2014-2018 \\
\hline Promedio (\%) & 7,7 & 6,9 \\
\hline Variación (\%) & & 0,8 \\
\hline
\end{tabular}

Fuente: Construcción personal.
Tabla 8. Variación de tasa de abandono anual en las escuelas secundarias de la Provincia de Córdoba en los periodos 2009-2013 y 2014-2018.

\begin{tabular}{|l|l|l|}
\hline Periodo & 2009-2013 & $\mathbf{2 0 1 4 - 2 0 1 8}$ \\
\hline Promedio (\%) & 6,1 & 5 \\
\hline Variación (\%) & \multicolumn{2}{|c|}{1,1} \\
\hline
\end{tabular}

Fuente: Construcción personal. 


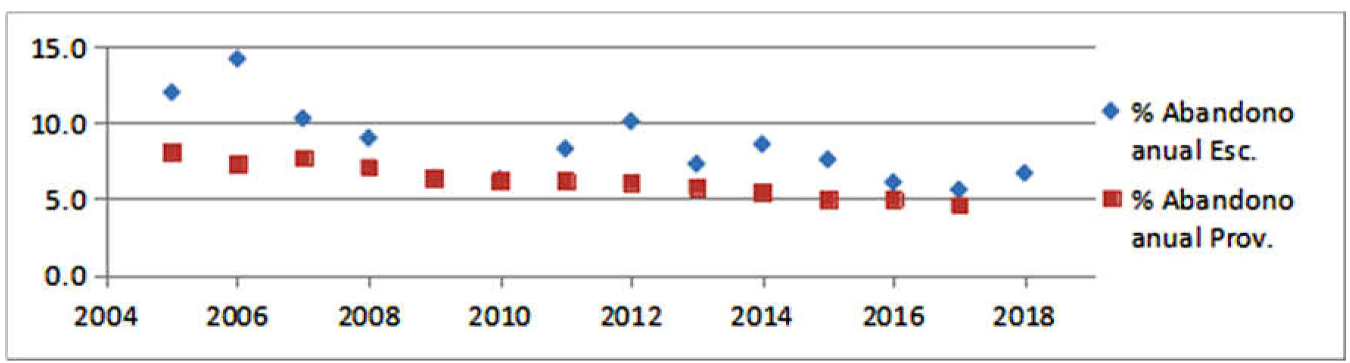

Figura 2. Tasa de abandono anual en la escuela secundaria estudiada (2005-2018).

Fuente: Construcción personal.

Respecto a la presencia de estudiantes con 34 inasistencias o más, encontramos que en el periodo 2005-2008 no se presentan estudiantes con más de 34 inasistencias, mientras que en el periodo 2009-2018 si se presentan (tabla 9).

Tabla 9. Presencia de estudiantes con 34 inasistencias o más por ciclo lectivo en la escuela secundaria estudiada (2005-2018).

\begin{tabular}{|l|l|l|l|l|l|l|l|l|l|l|l|l|l|l|}
\hline Ciclo lectivo & 2005 & 2006 & 2007 & 2008 & 2009 & 2010 & 2011 & 2012 & 2013 & 2014 & 2015 & 2016 & 2017 & 2018 \\
\hline Presencia (x)/Ausencia (-) & - & - & - & - & $\mathrm{x}$ & $\mathrm{x}$ & $\mathrm{x}$ & $\mathrm{x}$ & $\mathrm{x}$ & $\mathrm{x}$ & $\mathrm{x}$ & $\mathrm{x}$ & $\mathrm{x}$ & $\mathrm{x}$ \\
\hline
\end{tabular}

Fuente: Construcción personal.

\section{Estudiantes en situación de riesgo escolar}

En la escuela estudiada se presenta una tendencia a la disminución no lineal en la tasa de estudiantes en situación de riesgo escolar en el periodo 2005-2017 (tabla 10 y figura 3). Seguidamente se presenta una disminución del $15.3 \%$ en esta tasa en el periodo 2014-2018 (17.9\%) respecto al periodo $2009-2013(33.2 \%)$.

Tabla 10. Tasa de estudiantes en situación de riesgo escolar en la escuela secundaria estudiada en el periodo 2005-2018.

\begin{tabular}{|l|l|l|l|l|l|l|l|l|l|l|l|l|l|l|}
\hline Año & 2005 & 2006 & 2007 & 2008 & 2009 & 2010 & 2011 & 2012 & 2013 & 2014 & 2015 & 2016 & 2017 & 2018 \\
\hline Est. en situación de riesgo escolar (\%) & 41,7 & 33,3 & 23,3 & 37,7 & 38,6 & 39,0 & 33,2 & 25,4 & 29,8 & 12,9 & 15,0 & 23,4 & 21,0 & 17,4 \\
\hline
\end{tabular}

Fuente: Construcción personal.

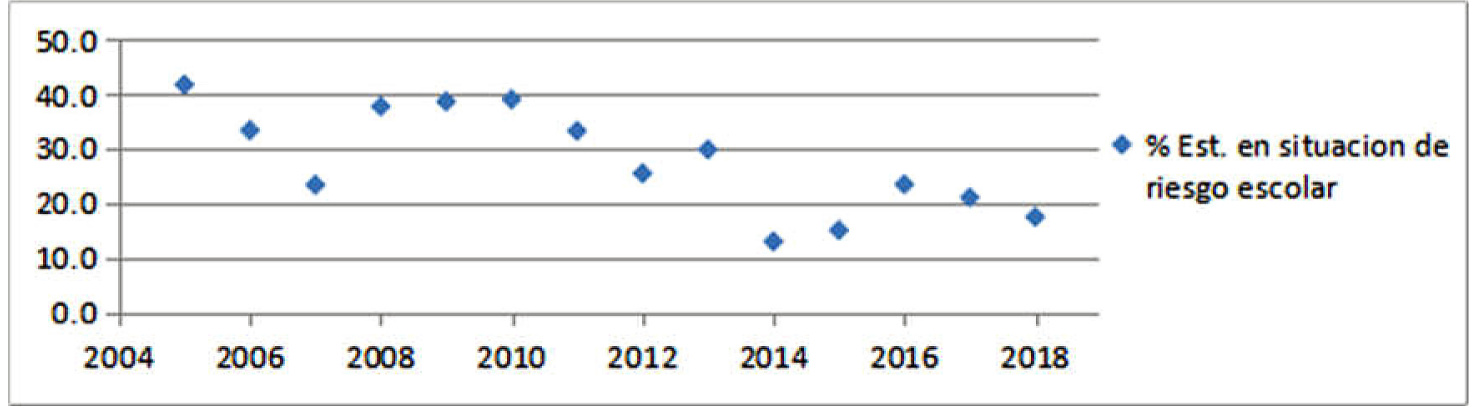

Figura 3. Tasa de estudiantes en situación de riesgo escolar en la escuela secundaria estudiada en el periodo 2005-2018. Fuente: Construcción personal. 
Tabla 11. Variación de tasa de estudiantes en situación de riesgo escolar en la escuela secundaria estudiada en los periodos 2009-2013 y 2014-2018.

\begin{tabular}{|l|l|l|}
\hline Periodo & 2009a2013 & 2014a2018 \\
\hline Promedio & 33,2 & 17,9 \\
\hline Variación & & 15,3 \\
\hline
\end{tabular}

Fuente: Construcción personal.

\section{Comportamiento de las trayectorias escolares según año de presencia del cargo de Coordinación de Curso}

Como observamos en la tabla 12, en el primer año de presencia del cargo de Coordinador de Curso en la escuela estudiada (2014) observamos una disminución marcada en las tasas de no-promoción y de estudiantes en situación de riesgo escolar respecto al año anterior (2013), cuando la institución educativa estudiada no disponía de dicho cargo. Seguidamente, respecto a la tasa de abandono escolar se presenta un incremento en comparación al año anterior, situación que no se mantiene en el segundo año de creación del cargo (2015), presentándose un incremento de las tasas de no-promoción y de estudiantes en situación de riesgo escolar y una disminución marcada de la tasa de abandono escolar anual.

En el tercer año de creación del cargo (2016) se presenta un incremento marcado en las tasas de no-promoción y de estudiantes en situación de riesgo escolar, mientras que disminuye la tasa de abandono escolar anual, situación que vuelve a cambiar en el cuarto año (2017), cuando las tasas de no-promoción y de estudiantes en situación de riesgo escolar presentan una disminución marcada, y en menor medida la tasa de abandono escolar anual. Finalmente, en el quinto año de creación del cargo de Coordinación de Curso (2018) se presenta una disminución en las tasas de no-promoción y de estudiantes en situación de riesgo escolar y un incremento en la tasa de abandono escolar anual.

Tabla 12. Comportamiento de las trayectorias escolares según año de presencia del cargo de Coordinación de Curso en la escuela estudiada.

\begin{tabular}{|l|c|c|c|c|c|}
\hline & Ter año (2014) & 2do año (2015) & 3er año (2016) & 4to año (2017) & 5to año (2018) \\
\hline Tasa de no promoción & - & + & ++ & - & - \\
\hline $\begin{array}{l}\text { Tasa de estudiantes en } \\
\text { situación de riesgo esc. }\end{array}$ & - & + & ++ & - & - \\
\hline $\begin{array}{l}\text { Tasa de abandono } \\
\text { escolar anual }\end{array}$ & + & - & - & - & + \\
\hline
\end{tabular}

— Disminución marcada, + + Incremento marcado, + Incremento y - Disminución.

Fuente: Construcción personal. 


\section{ANÁlisis DE RESUltados}

En el presente estudio encontramos una tendencia a la disminución en los tres indicadores empleados para analizar el impacto del trabajo del Coordinador de Curso en las trayectorias escolares en el periodo estudiado, a saber: disminución del $8.1 \%$ en la tasa de no-promoción, disminución de $0.8 \%$ en la tasa de abandono escolar anual y disminución en la tasa de estudiantes en situación de riesgo escolar del 15.26\%.

Comparativamente, la disminución de la tasa de no-promoción en la escuela estudiada $(8.1 \%)$ es marcadamente mayor que a nivel provincial $(2.2 \%)$, así como también a nivel de las escuelas técnicas $(2 \%)$ y a nivel departamental (4.5\%), por 5.9, 6 y 3.6 puntos porcentuales correspondientemente. Seguidamente, la disminución en la tasa de abandono escolar en la escuela estudiada $(0.8 \%)$ es menor que a nivel provincial $(1.1 \%)$ por 0.3 puntos porcentuales.

De este modo, si bien la disminución en la tasa de no-promoción en la escuela estudiada es marcadamente mayor que la sucedida a nivel provincial, escuelas técnicas y departamental, no observamos un impacto marcado en la tasa de abandono escolar (mientras que en la escuela estudiada la disminución es del $0.8 \%$, a nivel provincial es de $1.1 \%$ ). Seguidamente, al no contar con datos estadísticos respecto a la tasa de estudiantes en situación de riesgo escolar a nivel provincial, de las escuelas técnicas y departamental, no podemos extraer conclusiones al respecto.

En relación a los resultados cuantitativos encontrados, a partir de las entrevistas y el trabajo de campo realizado, surgen tres narrativas que buscan dar un marco de comprensión a los resultados encontrados.

\section{Primera narrativa: pobreza como}

\section{invariable estructural de la eficacia interna}

En primer lugar, al informarle al Coordinador de Curso acerca de la tendencia a la disminución en los tres indicadores analizados en esta investigación en el periodo estudiado se mostró sorprendido, desconociendo que en su escuela se presentaba dicha mejoría en los últimos años. En su lugar, solía mostrarse crítico hacia su trabajo, presentando una visión negativa acerca de los efectos de su quehacer en las trayectorias escolares, más allá de que se esforzara cotidianamente. Al consultarle las razones de dicha valoración, el Coordinador comentó: "No observo que algo mejore estructuralmente. Más allá de lo que hago, cada año veo que repiten y abandonan muchos chicos, sin cambiar nada. Es como una corriente muy fuerte que arrasa con todo, o los cambios son muy pequeñitos".

De modo similar, Finnegan y Serulnikov (2014) encuentran que los actores involucrados en otros programas socioeducativas (CAJ, Proyecto para la Prevención del Abandono Escolar, etc.) valoran los mismos, si bien se plantean dudas respecto a su efectividad en la escolarización. 
En este estudio los agentes escolares entrevistados señalaron que los problemas educativos de repitencia, abandono y problemas de comportamiento se deben a que las familias se encuentran ausentes o no saben acompañar o ayudar a sus hijos. Identifican que muchas familias de los estudiantes repitentes son pobres y no saben enseñarles el oficio de ser estudiantes de la escuela secundaria, al no haber terminado la primaria o secundaria. Un docente comenta: "Hacemos lo que podemos, con lo poco que tenemos. El Estado debería hacer más". De modo similar, Finnegan, Montesinos y Schoo (2019) encuentran estas mismas expresiones de forma frecuente en las escuelas de Salta y Mendoza que investigan.

Se desprende de lo anterior que la mayoría de los actores escolares reconocen una relación entre situación socio-económica familiar y trayectorias escolares, señalada en la bibliografía especializada (López, 2005; Dussel, 2008; CEPAL, 2008; Román, 2013; UNICEF, 2016; Aristimuño, 2017). Sin embargo se presenta contradicción en y entre los agentes escolares respecto a la comprensión de los problemas en el rendimiento interno del sistema educativo. Por un lado responsabilizan a las familias de los problemas de los estudiantes (Finnegan, Montesinos y Schoo, 2019); por otro lado responsabilizan al Estado respecto a la insuficiencia de políticas educativas y económicas, que mantiene en la pobreza a muchas familias. Finalmente, en pocos casos se auto-responsabilizan y evalúan críticamente su tarea educativa con miras a modificarla para obtener mejores resultados (Borzone y Rosemberg, 2000).

Específicamente, el Coordinador de Curso presentaba una comprensión macro-social de los problemas en el rendimiento interno de su escuela, entendiendo que la repitencia, abandono, ausentismo, etc., son problemas estructurales educativos y socio-económico (macro-social) y no solamente problemas individuales de algunos estudiantes y sus familias (micro-social).

Seguidamente, el Coordinador de Curso señaló que "el problema de los estudiantes que tienen bajo rendimiento, repiten y abandonan la escuela es tan complejo que casi no es posible hacer una diferencia", sintiéndose responsable por no poder ayudarlos, ya que ese es su trabajo. En este sentido, si bien el Coordinador se mostró crítico a las condiciones socioeconómicas de los problemas educativos, encontramos que se auto-responsabilizaba (Díaz y Pinto, 2017).

\section{Segunda narrativa: disminución del}

\section{abandono anual por indicación de la dirección}

Una segunda narrativa que surge respecto a la disminución en la tasa de abandono anual es que dicha disminución se debe a que la dirección de la escuela hace dos o tres años cesó de dejar alumnos libres (en condición de alumnos libres ${ }^{12}$ ) por inasistencias. Sin embargo, al

12 En el sistema educativo cordobés, las condiciones de los alumnos son regular o libre. Formalmente, un alumno que se matricula a inicio de año pasa a la condición de libre cuando incurre en: (a) 30 inasistencias, y (b) 20 sanciones disciplinarias (Debanne, 2015). 
analizar los registros de inasistencia del periodo 2005-2018 encontramos que no hay coincidencia entre las afirmaciones de los agentes escolares y los datos cuantitativos respecto a dicha fecha (ver tabla 9). En los registros de asistencia de preceptoría se encuentra que entre los años 2010 y 2018 hay estudiantes que concluyen su ciclo lectivo con entre 35 y 59.5 inasistencias. Estos alumnos deberían encontrarse en condición de alumnos libres cuando llegan a las 30 inasistencias, si se aplicara la legislación escolar (situación que explicaremos a continuación). Es importante aclarar que en los años 2005, 2006, 2007 y 2008 no se presentan estudiantes que finalicen su ciclo lectivo con más de 30 inasistencias y en el año 2009 un solo estudiante concluyó su ciclo lectivo con 34 inasistencias.

\section{Tercera narrativa: mejora de la eficacia interna como trabajo cooperativo y sinérgico}

Finalmente podemos construir una tercera narrativa en la cual la disminución en los estadísticos analizados se debería a las acciones realizadas por el Coordinador de Curso, en conjunto con una multiplicidad de actores escolares y extra-escolares.

Respecto a esto, por un lado el Coordinador de Curso valora las acciones educativas que realiza cotidianamente, expresando que cree que las mismas "pueden ayudar a los estudiantes en situación de riesgo escolar". Estas acciones son: co-coordinación de proyectos institucionales (proyecto de tutorías, ${ }^{13}$ proyecto de fortalecimiento de lecto-comprensión y proyecto de educación sexual integral); acompañamiento a estudiantes en situación de vulneración de derechos (violencia familiar, abuso sexual, problemas derivados de la discapacidad, abandono escolar, etc.); mediación de problemas de convivencia escolar, acompañamiento al Centro de estudiantes como docente asesor; facilitar grupos de juego, arte y oficios; compartir espacios cotidianos con los estudiantes, y trabajo con problemas emergentes (Acosta et al., 2018).

Por otro lado, las acciones que realiza el Coordinador son valoradas positivamente por muchos actores institucionales entrevistados (directivos, docentes y preceptores), sin embargo se presentan algunos actores que cuestionan la relevancia y urgencia de algunas de las acciones que realiza el Coordinador, así como también se muestran poco colaborativos; variaciones en los sentidos y valoración que también encontramos en Olmos (2016) respecto a otras políticas socioeducativas en escuelas de la Provincia de Córdoba.

13 El Coordinador de Curso señala como prioritario, "su mano derecha", el Proyecto de tutorías, proyecto institucional de la escuela estudiada que busca acompañar de forma personalizada las trayectorias escolares de los estudiantes en situación de riesgo escolar. En este proyecto los Acompañantes Pedagógicos trabajan con siete estudiantes de un mismo curso a lo largo de su ciclo lectivo. Los estudiantes son identificados a partir de reconocer su desempeño escolar en el ciclo lectivo anterior (problemas psicosociales, cantidad de materias no promocionadas en diciembre, repitencia y cantidad de inasistencias) así como también al final de cada trimestre, proyecto que es valorado por los estudiantes y docentes participantes. 
Más allá de estas contradicciones, según el análisis de documentos (planes de acción anuales del Coordinador de Curso), observamos que el Coordinador sostiene mayormente sin variaciones las líneas de acción a lo largo de los cinco años estudiados. Así mismo, si bien son acciones que son gestionadas por una persona (el Coordinador de Curso), las mismas son realizadas en articulación con actores de la escuela (docentes, preceptores, tutores, directivos y personal con pase en comisión) y extra-escolares (psicólogas, trabajadoras sociales y psicopedagogas de dispensarios, hospital regional e instituciones privadas). En ese sentido, el Coordinador de Curso reconoce que su trabajo es cooperativo y sinérgico.

Vinculado a lo anterior, esta escuela progresivamente incorporó nuevos cargos a su plantel en el periodo investigado (2014-2018): Coordinador y Talleristas del CAJ (desde el año 2016), Acompañantes Pedagógicos y Consejera del Programa Igualdad de Oportunidades ${ }^{14}$ (desde el año 2014), personal con cambio de actividad (desde el año 2017) y FAT ${ }^{15}$ (desde el año 2015). De este modo, es posible que el trabajo de estos nuevos actores institucionales incidiera estadísticamente en las trayectorias escolares, por lo cual no podemos afirmar que la mejora estadística se deba al trabajo del Coordinador de Curso. En su lugar podemos hipotetizar que se trataría de un trabajo colaborativo entre actores escolares y extra-escolares.

En ese sentido, si bien la escuela no tiene control sobre factores externos del fracaso escolar como es el nivel socioeconómico de las familias (Román, 2013; Secretaría de Educación Pública, 2012; UNICEF, 2016; Bottinelli, 2018), en el caso estudiado observamos que el trabajo cooperativo y sinérgico de los actores escolares y extra-escolares tendría un impacto estadístico positivo, logrando una tendencia a la disminución en los tres indicadores analizados (tasa de no-promoción, tasa de abandono escolar anual y tasa de estudiantes en situación de riesgo escolar). Pero no logra solucionar los problemas socioeducativos. En ese sentido, en el periodo estudiado (2005-2018) muchos niños y jóvenes atravesaron situaciones de riesgo escolar; por ejemplo, 379 estudiantes quedaron en condición de libres en la escuela estudiada.

Finalmente, es importante señalar que el trabajo colaborativo que realiza el Coordinador de Curso junto a otros actores presenta contradicciones, poniéndose en tensión dos lógicas socio-educativas: incluir o excluir a los estudiantes (D’Aloisio, Arce y Arias, 2018; Finnegan y Serulnikov, 2014; Ortiz y Zacarías, 2020).

14 Programa vigente para escuelas técnicas de la Provincia de Córdoba que dispone, por ejemplo, para escuelas con matrícula de entre 300 y 400 estudiantes, de tres cargos de Acompañantes Pedagógicos, que trabajan principalmente en tutorías, y un cargo de Consejera, que busca fortalecer la especialidad técnica realizando tutorías, organización de actividades de revalorización y promoción de la especialidad, etc.; quienes disponen de una carga horaria de cinco horas semanales cada uno.

15 Espacio curricular de Formación en Ambientes de Trabajo (FAT), cargo docente que disponen las escuelas técnicas para ese espacio curricular de 7o. año, cuando los estudiantes realizan pasantías o prácticas de profesionalización para titularse como técnicos de nivel medio. 
Esta situación se visibiliza con claridad en la polémica que periódicamente generan entre el personal de la escuela los estudiantes que incurren en más de 30 inasistencias no justificadas por razones médicas. Por un lado hay docentes, preceptores y directivos que quieren dejar libres a dichos estudiantes para que repitan y recursen el año, fundamentándose en las normativas vigentes que establece dicho procedimiento (Debanne, 2015), planteando como práctica cotidiana la queja. Por otro lado, otros actores institucionales flexibilizan dicha normativa, ${ }^{16}$ como sucede en otras escuelas de Argentina (UNICEF, 2019), planteando darles una segunda oportunidad, de modo que puedan seguir asistiendo a la escuela. Fundamentan su accionar en la situación de vulnerabilidad socio-familiares que tendrían esos estudiantes (pobreza, abandono de los padres, problemas familiares, etc.) y, recientemente, referencian los lineamientos establecidos en las "Pautas para la articulación y la coordinación de acciones en el marco de la protección de derechos" (Ministerio de Educación y Ministerio de Justicia y Derechos Humanos, 2017). ${ }^{17}$ Desde este documento ministerial, si el equipo directivo de una escuela decide que un alumno curse en condición de alumno libre, podría interpretarse como una situación de vulneración del derecho a la educación de ese niño (Congreso Argentino, 2006), al impedírsele la asistencia diaria a la escuela. En este marco, el Coordinador de Curso, junto a preceptores, docentes y directivos, realiza numerosas acciones cotidianas para abordar esta problemática (comunicación telefónica y entrevista con la familia, articulación con trabajador social de la localidad donde viven los estudiantes, informes a inspección, etc.). En este sentido, muchas veces la escuela se presenta como un campo social complejo, contradictorio y, a veces, incoherente (Bottinelli, 2018).

\section{Conclusiones}

En el presente estudio analizamos el impacto del cargo de un Coordinador de Curso a lo largo de cinco años en las trayectorias escolares, encontrando un efecto positivo en las tasas de no-promoción en la escuela, de abandono escolar y de estudiantes en situación de riesgo. Seguidamente caracterizamos el comportamiento de las trayectorias escolares según el año de presencia del cargo de Coordinación de Curso en la escuela estudiada. Finalmente construimos tres narrativas que buscan dar un marco de comprensión a los resultados encontrados desde el punto de vista de los actores escolares.

16 Por ejemplo, una práctica informal que sucede en la escuela estudiada desde preceptoría es "perdonarles un cuarto o media falta", sin pasar al registro de asistencia las llegadas tarde, como una forma de "cuidar", según relata un preceptor.

17 Documento presentado a los equipos directivos, docentes y Coordinadores de Curso de la Provincia de Córdoba en el año 2018 en reuniones a cargo del EPAE, apoyado por diferentes profesionales de organismos públicos y privados, locales y regionales, de la zona donde se ubica la escuela (dispensario, EPAE, área de Niñez, Adolescencia y Familia, centros terapéuticos privados, etc.). 
Encontramos que muchos de los actores escolares entrevistados refieren a la pobreza como una invariable estructural de la eficacia interna del sistema educativo. En ese sentido, si bien la escuela no puede abordar las condiciones socio-económicas de las familias, en el caso estudiado observamos una tendencia a la disminución de los indicadores internos analizados, pudiendo hipotetizar que el trabajo cooperativo y sinérgico entre los actores escolares y extra-escolares lograría un impacto estadístico positivo.

A partir de estos resultados es posible pensar que no se lograría resolver estructuralmente los problemas socioeducativos con el actual diagrama organizacional de la escuela secundaria (Acosta et al., 2018; Martino y Del Valle, 2011; Martino, 2012) sin contar con la cantidad de cargos de Coordinadores de Cursos necesarios para cumplir con los objetivos del programa (UEPC, 2014), así como también de otros cargos (tutores, preceptores, talleristas del CAJ, gabinetes psicopedagógicos, etc.), lo cual solo es posible mediante políticas educativas de inclusión social, como política social estatal (Ortiz y Zacarías, 2020).

Entendemos que las conclusiones arribadas en este estudio son parciales y es necesario realizar otros estudios. En primer lugar, se hace necesario realizar un estudio de casos múltiples, incluyendo escuelas de diferentes departamentos de la Provincia de Córdoba, así como también un estudio correlacional cuasi-experimental que permita evaluar la incidencia específica de la presencia del cargo de Coordinador de Curso en las trayectorias escolares y su relación estadística con el trabajo colaborativo y sinérgico entre los diferentes actores escolares. En segundo lugar, se requiere replicar el estudio en otras escuelas para complejizar y comparar la caracterización estadística del comportamiento de los indicadores de las trayectorias escolares según el año de presencia del cargo de Coordinación de Curso.

Valoramos que los indicadores del rendimiento interno del sistema educativo aquí empleados son herramientas analíticas útiles para evaluar las trayectorias escolares a nivel institucional y las políticas socioeducativas a nivel regional. Seguidamente, estos indicadores son predictores del abandono escolar (Secretaria de Educación Pública, 2012; Aristimuño, 2017; Morrone, Cura y Pissinis, 2018; Adrogué y Orlicki, 2018) y permiten observar, evaluar y tomar decisiones acerca del trabajo escolar diario.

De este modo, reconociendo que en cada escuela se realizan múltiples proyectos y líneas de acción, pero no sabemos con certeza si funciona y qué es lo que funciona, el presente estudio pretende ser un aporte a los actores escolares que trabajan diariamente en las trayectorias escolares, en tanto procedimiento de evaluación replicable en cada escuela, útil para evaluar a mediano y largo plazo sus líneas de acción.

En este sentido, reconociendo que continúan existiendo miles de niños y adolescentes que repiten y abandonan cada año la escuela secundaria y que las condiciones de pobreza se agudizan, se hace necesario y urgente profundizar la evaluación del 
impacto de las actuales políticas educativas y socioeducativas para conocer qué es lo que funciona, y continuar construyendo alternativas eficaces para transformar el mundo (Freire, 2012).

\section{REFERENCIAS}

Acosta, D., Bertea, F., Correa, G., Dalla Costa, L., y Hennao Blasco, I. (2018). Diario de escuela. Narraciones de Coordinadorxs de Curso. Córdoba: Editorial Babel. Recuperado de: https://flacso.org.ar/wp-content/ uploads/2018/09/Diario-de-escuela-narraciones-decoordinadorxs-de-escuela.pdf.

Adrogué, C., y Orlicki, M.E. (2018). Estudiantes en riesgo. Un análisis de los factores asociados al abandono de la escuela secundaria en la Argentina desde 2003. Pilquen, 15(1), 21-32. Recuperado de: http://revele. uncoma.edu.ar/htdoc/revele/index.php/psico/ article/view/1914.

Área de Estadística e Información Educativa (2015). Educación común. Nivel secundario. Sintesis estadística $N^{\circ}$ 17. Dirección General de Planeamiento, Información y Evaluación Educativa, Ministerio de Educación, Gobierno de la Provincia de Córdoba.

Área de Información Educativa (2008). Educación común. Nivel medio. Sintesis estadística nro. 2. Años 2003-2007. Ministerio de Educación, Gobierno de la Provincia de Córdoba.

Área de Información Educativa (2012). Educación común. Nivel medio. Sintesis estadística nro. 11. Años 2007-2011. Ministerio de Educación, Gobierno de la Provincia de Córdoba.

Aristimuño, A. (2017). El abandono escolar, afinando el conocimiento sobre sus características y cómo superarlo. Un caso raro en América Latina. Diálogos Pedagógicos, 15(30), 37-59. DOI: http://dx.doi. org/10.22529/dp.2017.15(30)02.

Bell, S. A., y Aggleton, P. (2016). Interpretive and ethnographic perspectives - alternative approaches to monitoring and evaluation practice. Nuev York: Routledge.

Bottinelli, L. E. (2018). Conocimiento y politicas educativas: una mirada sobre los estudios de eficacia escolar. Buenos Aires: Ministerio de Educación de la Nación.

Bolívar, A. (2005). Equidad educativa y teorías de la justicia. REICE. Revista Iberoamericana sobre Calidad,
Eficacia y Cambio en Educación, 3(2), 42-69. Recuperado de: https://revistas.uam.es/index.php/reice/article/ view/5555/5974.

Borzone de Manrique, A. M., y Rosemberg, C. R. (2000). Leer y escribir entre dos culturas: el caso de las comunidades kollas del noroeste argentino (Programa YACHAY-OCLADE). Buenos Aires: Aique Grupo Editor S. A.

Buchbinder, N., McCallum, A., y Volman, V. (2019). El estado de la educación en la Argentina. Observatorio Argentinos por la Educación. Recuperado de: https:/ / cms.argentinosporlaeducacion.org/media/reports/ El_estado_de_la_educacion_Argentina.pdf.

CEPAL [Comisión Económica para América Latina y el Caribe] (2008). Panorama social de América Latina. Chile: Naciones Unidas.

CIPPES [Centro de Investigaciones Participativas en Políticas Económicas y Sociales] (2018). La infantilización de la pobreza crece. Córdoba entre las 3 peores provincias. Recuperado de: http://www.cippes.org/noticia/20/ la-infantilizacion-de-la-pobreza-crece-crdoba-entrelas-3-peores-provincias.

CIPPES (2019). Crecimiento y profundización de la pobreza en la provincia de Córdoba. Recuperado de: http://www. cippes.org/noticia/25/crecimiento-y-profundizacinde-la-pobreza-en-la-provincia-de-crdoba

Cohen, E., y Franco, R. (1992). Evaluación de proyectos sociales. México: Siglo Veintiuno.

Congreso Argentino (2006). Ley de Educación Nacional $N^{\circ} 26.206$. Buenos Aires.

D’Aloisio, F., Arce, V., y Arias, L. (2018). Las trayectorias escolares juveniles en clave biográfica. Un análisis desde las condiciones de cuidado y de vulnerabilidad. En H. L. Paulín, G. García Bastán, F. D’Aloisio y R. Carreras (coords). Contar quiénes somos. Narrativas juveniles por el reconocimiento (pp. 49-79). Córdoba: TeseoPress.

Debanne, R. (2015). Manual de normativa y legislación escolar Nivel medio Córdoba. Córdoba: Punto de Apoyo. 
De Souza Minayo, M. C. (2009). La artesanía de la investigación cualitativa. Buenos Aires: Lugar Editorial.

Díaz López, C., y Pinto Loría, M. (2017). Vulnerabilidad educativa: un estudio desde el paradigma socio crítico. Praxis Educativa, 21(1). DOI: http://dx.doi. org/10.19137/praxiseducativa-2017-210105.

DiniECE [Directora Nacional de Información y Evaluación de la Calidad Educativa] (s.f.). Guia para evaluación de programas en educación. Buenos Aires: Ministerio de Educación.

Dirección General de Educación Técnica y Formación Profesional (2018). Informe correspondiente al IPET $N^{\circ}$ XX. Córdoba: Ministerio de Educación.

Dirección General de Estadística y Censo (2019). Repitencia y sobreedad: permanece la tendencia decreciente en las aulas de nivel medio. Gobierno de la Provincia de Córdoba. Recuperado de: https://estadistica. cba.gov.ar/publicacion-sfi/repitencia-y-sobreedadpermanece-la-tendencia-decreciente-en-las-aulasdel-nivel-medio/.

DNPS [Dirección Nacional de Políticas Socioeducativas] (s.f.a). Cuaderno No 1. Principios. Metas. Programas. Buenos Aires: Ministerio de Educación, Presidencia de la Nación.

DNPS (s.f.b). Apoyo y acompañamiento socioeducativo para la infancia, la adolescencia y la juventud. Buenos Aires: Ministerio de Educación. Presidencia de la Nación.

Dussel, I. (2008). Desigualdad social y desigualdad educativa. Programa interdisciplinario de investigaciones en educación UEPC. Recuperado de: http:/ / www.uepc. org.ar/conectate/desigualdad-social-y-desigualdadeducativa-ines-dussel/.

Fals Borda, O. (1985). Conocimiento y poderpopular. España: Siglo Veintiuno.

Finnegan, F., y Serulnikov, A. (2014). Las contribuciones de las politicas socioeducativas para el nivel secundario. Las perspectivas de los actores locales. Buenos Aires: Ministerio de Educación de la Nación.

Finnegan, F., Montesinos, M. P., y Schoo, S. (2019). Politicas de revinculación y terminalidad escolar de la educación secundaria. Reflexiones a partir de dos experiencias provinciales: Trayecto de escolaridad protegida y polo de reingreso. Buenos Aires: Ministerio de Educación de la Nación.

Freire, P. (2012). Pedagogía de la indignación. Buenos Aires: Siglo XXI.
Gibbs, G. (2012). El análisis de datos cualitativos en investigación cualitativa. Madrid: Ediciones Morata.

Gobierno de la Provincia de Buenos Aires (2019). Escuelas promotoras. Evaluación de impacto. Buenos Aires: Ministerio de Educación.

Gvirtz, S., y Oría, A. I. (2010). Evaluar el rendimiento interno y académico: un desafío para la macro y la micro política. Lecciones a partir de un estudio de caso. Revista Iberoamericana de Evaluación Educativa, 3(2), 127-144. Recuperado de: http://www.rinace.net/riee/ numeros/vol3-num2/art7.pdf.

Jara, O. H. (2012). Sistematización de experiencias, investigación y evaluación: aproximaciones desde tres ángulos. Revista Internacional sobre Investigación en Educación Glocal y para el Desarrollo, 1, 56-70. Recuperado de: https://dialnet.unirioja.es/servlet/ articulo?codigo $=6368512$.

Lassiter, L. E. (2005). The Chicago Guide to Collaborative Ethnography. EEUU: University of Chicago Press.

Lavalle, M. P. (2015). El Coordinador de Curso: nueva figura, otra mirada en las instituciones educativas secundarias. Revista Contextos de Educación, 15(19), 31-41. Recuperado de: http://200.7.136.16/ojs/index.php/ contextos/article/view/389/393.

López, N. (2005). Equidad educativa y desigualdad social. Desafíos de la educación en el nuevo escenario latinoamericano. Buenos Aires: UNESCO.

Martino, A. (2012). Escolarización, función pedagógica y trabajo escolar de la escuela secundaria. Algunos apuntes desde los Coordinadores de Curso. Cuadernos de Educación, 10(10), 1-12. Recuperado de: https:// revistas.unc.edu.ar/index.php/Cuadernos/article/ view/4522.

Martino, A., y Del Valle Uanini, M. (2011). Extensión en la escuela secundaria: primeras notas sobre la experiencia de acompañamiento a la institucionalización de los "Coordinadores de Curso". Revista e+e, 3(3). Recuperado de: http://revistas.unc.edu.ar/index.php/ $\mathrm{EEH} /$ article/view/5528.

Maturo, Y. (2018). El derecho a la educación técnico profesional. Efectos de la dinámica exclusión incluyente en una escuela técnica de Córdoba. Educación, Formación e Investigación, 4(7), 55-79. Recuperado de: http://ppct.caicyt.gov.ar/index.php/efi/article/ view/13396/45454575759312. 
Ministerio de Educación (2008). Estudio de impacto: Programa "Escuela para jóvenes" (período 2001-2007). Investigación 1. Córdoba: Área de Investigación Educativa, Subsecretaría de Promoción de Igualdad y Calidad Educativa.

Ministerio de Educación (2009). Resolución 1613/09. Gobierno de la Provincia de Córdoba.

Ministerio de Educación (2015). Educación común nivel secundario. Sintesis estadística No 17. Años 2010 al 2015. Dirección General de Planeamiento, Información y Evaluación Educativa. Córdoba: Área de Estadística e Información Educativa.

Ministerio de Educación (2018). Estadísticas de la educación 2018. Dirección General de Planeamiento, Información y Evaluación Educativa. Córdoba: Área de Estadística e Información Educativa.

Ministerio de Educación de la Nación (2017). Anuario Estadístico Educativo. Buenos Aires: Dirección de Información y Estadística Educativa. Recuperado de: https://www.argentina.gob.ar/sites/default/files/ anuario-estadistico-datos-2018-web.pdf.

Ministerio de Educación de la Nación (2018). Anuario Estadístico Educativo. Buenos Aires: Dirección de Información y Estadística Educativa. Recuperado de: https://www.argentina.gob.ar/sites/default/files/ anuario-estadistico-datos-2018-web.pdf.

Ministerio de Educación y Ministerio de Justicia y Derechos Humanos (2017). Pautas para la articulación y coordinación de acciones en el marco de la protección de derechos. Córdoba.

Montero, M. (2006). Teoría y práctica de la psicología comunitaria. Buenos Aires: Paidós.

Morrone, A., Cura, D., y Pissinis, A. (2018). Informe del progreso educativo de Argentina. Argentina en deuda educativa. Aprender es un derecho. Buenos Aires: Proyecto Educar y Diálogo Interamericano.

Olmos, A. (2016). Políticas socioeducativas y trabajo docente. La gestión escolar, entre la acumulación de proyectos compensatorios y la práctica de la inclusión educativa (Córdoba, Argentina, 2000-2010). Revista Administración Pública y Sociedad, 1, 48-59. Recuperado de: https://revistas.unc.edu.ar/index.php/APyS/ article/view/14643.

Ortiz Huerta, M. G., y Zacarías Gutiérrez, M. (2020). La inclusión educativa en el sistema neoliberal capitalista.
IE Revista de Investigación Educativa de la REDIECH, 11, e-794. doi: 10.33010/ie_rie_rediech.v11i0.794.

Paredes, D. (2018). El nivel secundario en el ámbito rural: análisis cuantitativo sobre sus tendencias recientes. Buenos Aires: Ministerio de Educación de la Nación.

Presidencia de la Nación Argentina (1970). Decreto $N^{\circ} 3$. Sistema Estadístico Nacional. Buenos Aires.

Prieto Toraño, B. (2015). El camino desde la vulnerabilidad escolar hacia el desganche educativo. El papel de las escuelas de segunda oportunidad en la estrategia contra el abandono educativo. Revista de Currículum y Formación del Profesorado, 19(3), 110-125. Recuperado de: https://www.redalyc.org/pdf/567/56743410008. pdf.

Redacción Córdoba (2019, 4 abr.). Córdoba: trabajadores de programas socioeducativos denuncian vaciamiento. En La Izquierda Diario. Recuperado de: http://www. laizquierdadiario.com/Cordoba-trabajadores-deprogramas-socioeducativos-denuncian-vaciamiento.

Rivas, A. (2015). América Latina después de PIS A: lecciones aprendidas de la educación en siete países 2000-2015. Buenos Aires: CIPPEC.

Rodríguez Gómez, G., Gil Flores, J. y García Jiménez, E. (1996). Metodología de la investigación cualitativa. Málaga: Aljibe.

Román, M. C. (2013). Factores asociados al abandono y la deserción escolar en América Latina: una mirada en conjunto. Revista Iberoamericana sobre Calidad, Eficacia y Cambio en Educación, 11(2), 1-27. Recuperado de: https://www.redalyc.org/pdf/551/55127024002.pdf.

Ritacco Real, M., y Amores Fernández, F. A. (2016). Estudiantes en riesgo de exclusión educativa en secundaria. Percepciones del profesorado implicado en programas extraordinarios de prevención del fracaso escolar. Enseñanza y Teaching, 34(1), 137-160. DOI: $10.14201 /$ et2016341137160.

Sabuda, F. G. (2009). ¿Quién es vulnerable en la escuela? Análisis territorial de rendimiento educativos y contexto sociocultural en el partido de General Pueyrredón, Argentina. Cuadernos de Geografía: Revista Colombiana de Geografía, 18, 45-57. DOI: https://doi. org/10.15446/rcdg.n18.13018.

Secretaría de Educación Pública (2012). Reporte de la Encuesta Nacional de Deserción en la Educación Media Superior. México. 
Serra, M. S., y Canciano, E. (2006). Las condiciones de enseñanza en contextos críticos. Buenos Aires: Ministerio de Educación.

Taylor, S. J., y Bogdan, R. (1985). Introducción a los métodos cualitativos de investigación. España: Paidós.

Terigi, F. (2015). Aportes de la investigación sobre políticas educativas y trayectorias escolares en la escuela secundaria. En D. Pinkasz, La investigación sobre educación secundaria en la Argentina en la última década (pp. 94-108). Ciudad Autónoma de Buenos Aires: FLACSO Argentina.

Torres de Torres, A. (2016). Reinvención de lo comunitario: Hacia una ciencia domiciliada en América Latina. Córdoba: Ed. Agora Editorial.

UEPC [Unión de Educadores de la Provincia de Córdoba] (2014). El nivel secundario en Córdoba: análisis de sus tendencias y transformaciones: 2003-2013. Córdoba: Alaya Servicio Editorial.

UNICEF [Fondo de las Naciones Unidas para la Infancia] (2016). Estado de situación de la niñez y la adolescencia en Argentina. Argentina. Recuperado de: https://www.unicef.org/ $\operatorname{argentina/media/2211/file/SITAN.pdf.~}$

UNICEF (2019). Los efectos de la situación económica en la niñezy adolescencia en Argentina. Una aproximación cualitativa. Recuperado de: https://www.unicef.org/argentina/informes/ efectos-situacion-economica-ninez-adolescencia-argentina.

Vega, V. S. (2017). Estudiantes de educación media superior y vulnerabilidad social, una experiencia de investigación-acción. IE Revista de investigación educativa de la REDIECH, 7(13), 94-106. Recuperado de: http://www. scielo.org.mx/scielo.php?script=sci_arttext\&pid=S2448$85502016000200094 \& \operatorname{lng}=$ es\&tlng $=$ es.

Cómo citar este artículo:

Bertea, F. (2020). Evaluación de políticas socioeducativas: impacto del cargo de Coordinador de Curso en las trayectorias escolares en una escuela secundaria pública técnica de Córdoba (Argentina). IE Revista de Investigación Educativa de la REDIECH, 11, e904. doi: https://doi.org/10.33010/ie_rie_rediech.v11i0.904. 